\title{
Environmental Problems and Countermeasures for Sustainable Development in a Declining Mining City Tongchuan
}

\author{
Zhao Aning*, Wang Jianhui, Chen Huaqing and Zhang Jianghua \\ ${ }^{1}$ Xi'an Center of China Geological Survey, Xi'an, 710054, China \\ 272376680@qq.com \\ * The corresponding author
}

Keywords: Declining mining city; Tongchuan; Environmental problems; Countermeasures

\begin{abstract}
Tongchuan is a resource-based city with coal, cement and clay minerals production. The development of mining industry has made a great contribution to the social and economic development of the city. With the depletion of mineral resources, the city faces two kinds problems: First, for a long time of mineral resources exploitation, the natural landscape has been deeply damaged, and many problems such as forest vegetation destruction, environmental pollution and geological disasters have greatly increased; the second is economic growth of mineral resources industry began to decline. So this city needs the alteration of industrial structure, and a large number of labor transfer. In this paper, we explained the types of serious environmental problems caused by mining development based on Tongchuan mine geological environment survey. Accordingly, we discussed the countermeasures of mine geological environment governance and the sustainable development of the economy.
\end{abstract}

\section{Introduction}

Tongchuan is a medium-sized mining city with resource development as its pillar industry and its coal resources have been mined for thousands of years. Since 1955, the cumulative production of raw coal has reached 360 million tons. The historical subjects are invested by the state and the production profits are benefit to the state, which has made important contributions to the national construction and local economic development. But the traditional extensive mode of development with high consumption, high emission and low efficiency has led the development without governance. Taoyuan, Shijiahe Mine and Jiaoping mine were exhausted and bankrupt, and a large number of small coal, limestone and clay mines were shut down by the government due to the vegetation production laws. It caused no corporation response for mine geological environment governance. [1]. Therefore, during decades of development, numerous and serious mine geological environment problems are needed to be solved urgently by the Tongchuan city and it restricts the further development of social economy in this city. Accordingly, identifying the status of mine environmental resources exhausted city, exploring the way of governance, studying its future availability, have an extremely important significance for the transformation of the city and promote the sustainable development of regional economy.

\section{Overview of Tongchuan City}

Physical Geography. Tongchuan City is located in the middle region of Shaanxi province, and the junction zone between Guanzhong Plain and Northern Shaanxi Loess Plateau. It contains three districts, one county (including Wangyi District, Yaozhou District, Yintai District, Yijun County) and a provincial economic and technological development zone, governing a total area of $3882 \mathrm{~km} 2$. The total population is 860 thousand, among which the non-agricultural population is 450 thousand, and the urbanization level is $53 \%$. Tongchuan is a warm temperate semi-arid continental monsoon climate with an average annual temperature of 10.6 degrees, a maximum temperature of 37.7 degrees (June), and a minimum temperature of -18.2 (January). The average annual precipitation $588 \mathrm{~mm}$, of which $54 \%$ of the annual rainfall concentrated from July to September [2]. 
Socioeconomic Overview. According to the statistics in 2008, the city's coal production is 17 million and 460 thousand tons, occupying $8.22 \%$ of the province's total coal production, coal mining and mineral processing industry accounted for $31 \%$ of the total industrial production value. More than half of the employees in the city's industries are the coal mining and mineral processing industry practitioners, and accounting for $33 \%$ of the employees of different types of units. The total ratio of employees is over $7 \%$.

According to statistics, Tongchuan city contains 285 mines of coal, metallurgy, building materials, including 183 coal mines, 7 large sized mines, 10 medium-sized mines and 5 of them have been closed or bankrupt; 166 small mines, and74 have been closed or shut down.

The city contains 56 limestone mines, 1 large, 1 medium-sized, and others are small sized mines, 14 mines have been closed.

The city contains 2 state-owned clay mines, including 1 medium-sized and 1 small sized. The two state-owned loess mines are medium-sized mines. The 2 construction sand mines are individual small enterprises. The 1 stone mine is individual small enterprises. The 13 clay mines for brick and tile are small enterprises, all of which are collective enterprises except 1 , and 3 of them are closed. Up to now, 123 mines were closed or bankrupted. There are 150 mines are still in production [3]. (Table 1)

Table 1 Statistics of the number of mining enterprises in Tongchuan

\begin{tabular}{ccccc}
\hline & State owned & Privately owned & Others & Total \\
\hline Coal mine & 12 & 10 & 30 & 62 \\
Limestone mine & 3 & 15 & 15 & 33 \\
Clay mine & 2 & 33 & 20 & 55 \\
Total & 17 & 58 & 65 & 150 \\
\hline
\end{tabular}

\section{Present Situation of Geological Environment in Tongchuan}

Primary Geological Environment Problems. The old city of Tongchuan are Wangyi district and Yintai District. The two districts are located in a "Y" formed loess gully with the width of 500-1500 meters, the terrain is rugged, the geological environmental problems are complex. Because of the large distribution of weak rock formations such as mudstone and coal seam in the area, the shear strength of rock mass in the whole area decreases especially in the infiltration of rain or the infiltration of groundwater, which can cause landslide and other geological disasters. The widespread Aeolian loess is collapsible, especially the Ma Lan loess with vertical joints, large porosity, loose, is prone to collapse and uneven settlement. Therefore, under natural conditions, landslides, soil erosion are in high potential in Tongchuan city.

According to incomplete statistics, since 1980s, more than 100 medium-sized geological disasters occurred in Tongchuan City, which caused 240 people death and 100 million Chinese Yuan in direct economic losses. Additionally, $70 \%$ of geological disasters are caused by human engineering activities. For example, on November 8, 1982, a loess landslide near Wanggu village in Wangyi District killed 4 people, injured 15 people. In 1985, the landslide sliding again, and 309 houses were destroyed. This slide caused a huge economic losses over 10 million Yuan. In September 29, 1984, a slope over 65,000 m3 collapsed in Yintai District, destroyed 23 houses and 50 people died. The abominable geological environment condition in the whole area is the main cause of the geological disaster which induced great losses to the social and economic development of the whole city.

Mine Geological Environment Problems. The mineral resources exploration of the Tongchuan City have made a significant contribution to the national and local economic development, as well as suffering the disorderly exploitation and extensive development for few decades. On one hand, it accelerated the rapid depletion of mineral resources; on the other hand, it also triggered and aggravated the deterioration of the environment, geological disasters such as mine geological environment problems in mining areas. Coal production areas of mining subsidence range is huge, massive destruction of arable land, the land collapse damaged roads, well water level dropped or 
dry, causing problems in drinking water. The collapse of the goaf leads to some landslide disasters in the massif and loess gully. Waste rock area, slump, spontaneous combustion and other serious problems. Clay mine, open pit mining caused by the destruction of land, bare soil; layout in the road, scenic area, cement limestone mine and its surrounding strip mining in bare rock, the destruction of vegetation, seriously affect the visual landscape, tourism scenic highway.

111 geological disasters are located in the city of Tongchuan, including 110 coal mines and one limestone mine. Main disaster types are ground subsidence, ground fissures, others are small-scaled collapse, landslide and debris flow. The disasters affect areas cover 3073.8 acres, cause over 12 million yuan of economic losses, and killed 16 people. The mined out areas of coal mines are $175.50 \mathrm{~km} 2$, and the area of ground subsidence areas are covering $157.20 \mathrm{~km} 2$. The occupation areas of the mines are $187.32 \mathrm{~km} 2$, but the recovery areas are only $23.38 \mathrm{~km} 2$, which is $12.4 \%$ of the occupied and destroyed area. The annual discharge of waste rock and stone is over 1 million tons, and the annual comprehensive utilization is near 320000 tons, with a total accumulation of 31303700 tons. The annual discharge of waste water and waste water is $4732700 \mathrm{~m} 3$, and the annual recycling capacity is $772800 \mathrm{~m} 3$.

As of 2009, there were 324 geological hazard spots in the whole city, and the geological hazards such as landslide, collapse, ground fissure and ground subsidence occurred frequently in the mining area, and 60000 people were threatened by the mined out area [4].

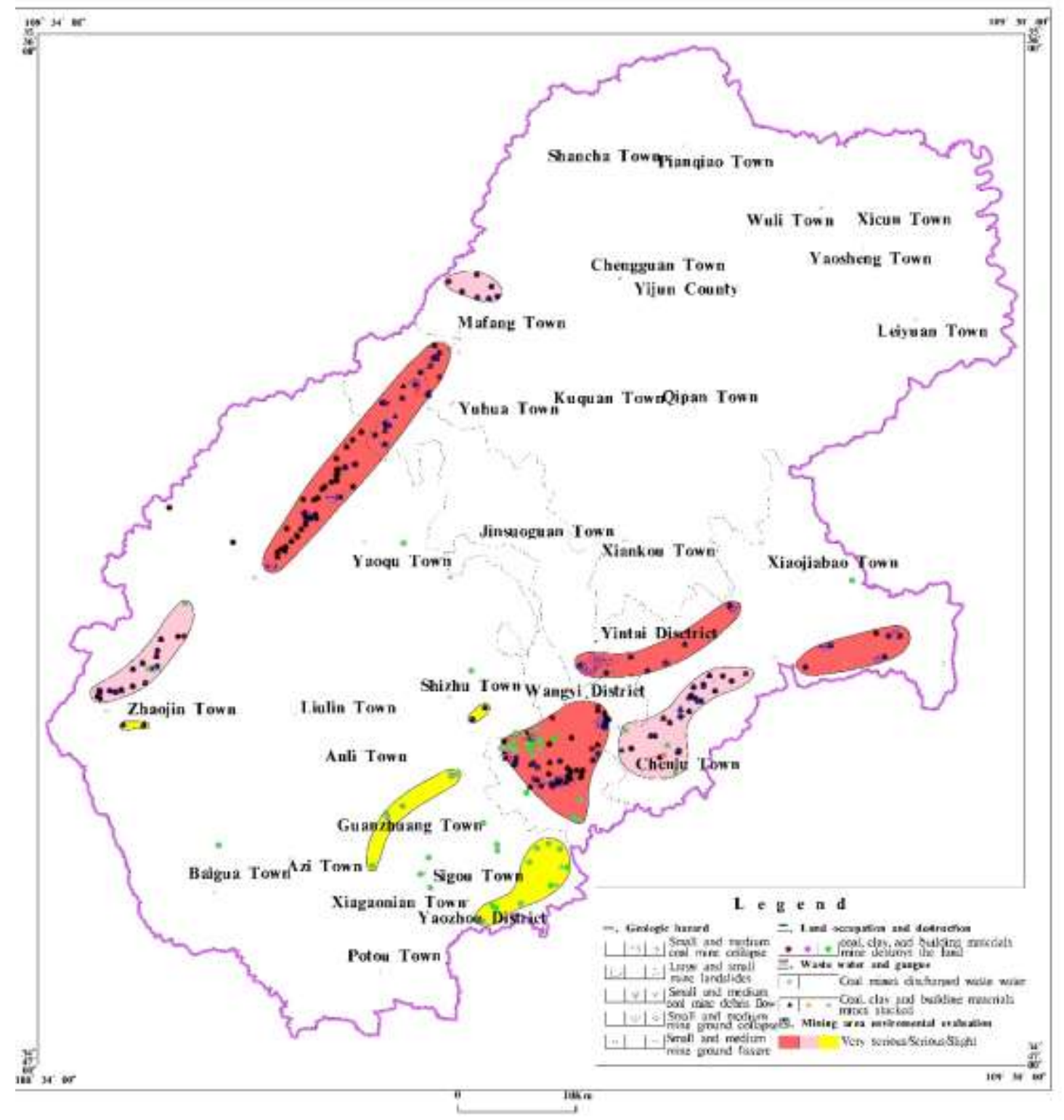

Figure1. Finite Distribution map of mine geological environment in Tongchuan City 
Main Geological Environment Problems in Coal Mining Area. The coal mines is covering $387.2 \mathrm{~km} 2$, which is divided into the Permo Carboniferous coal mining area and the Jurassic coal mining area. East part of the Tongchuan old urban area, the Carboniferous Permian coal resources reign, mainly contain Dongpo duck mouth, Huashan, Taoyuan, Kim Wang Shiao, three, historian Tong River, the current Mining Bureau under the Taoyuan, three in the cave, historians River Mine has closed pit due to resource depletion; the west area of the old city of Tongchuan, the main coalfield including Chen Jiashan, Xiashijie, Jiao Ping and Yuhua Coal Mine, which has China Jiaoping open-pit mine have shut down.

The main geological environment problems of coal resource development including ground subsidence, ground fissures in the underground mining area, mountain and gully edge collapses, landslide and debris flow geological hazards; destruction of arable land, destruction of buildings and roads caused by the uneven surface, affecting traffic safety.

Coal mines in and around Tongchuan city, including Taoyuan, Sanlidong, Wang Jiahe, Shi Jiahe, have caused surface subsidence, ground fissures and destroyed farmland, roads, village house (Fig. 2 ), and mining activities also caused gully edge damage, landslide, collapse. In the east part of the city, gangue spontaneous combustion, soil erosion, land loose, waste slumping seriously affected the city construction and residential ecological environment security [5]. In 1982, about 4,000,000 yuan was spent on the control of the landslide in the Jiaoping coal mine. Yuhua Coal Mine Industry Square mountain slip, endangering the mining area of 160 houses, 98 miners, 392 people evacuated, Yuhua mine road damage, anti-slide pile inclination increased, coal production is seriously affected. Yuhua Coal Mine, Wang Shiao coal mine, Dongpo coal mine collapse caused 8 deaths; 2 people died in the landslide Dongpo coal mine coal mining subsidence, Wang Yiqu Huang Town 2 deaths. The collapse of the ground caused the collapse of the villagers' cave in the village near the plateau, causing 2 deaths [6].
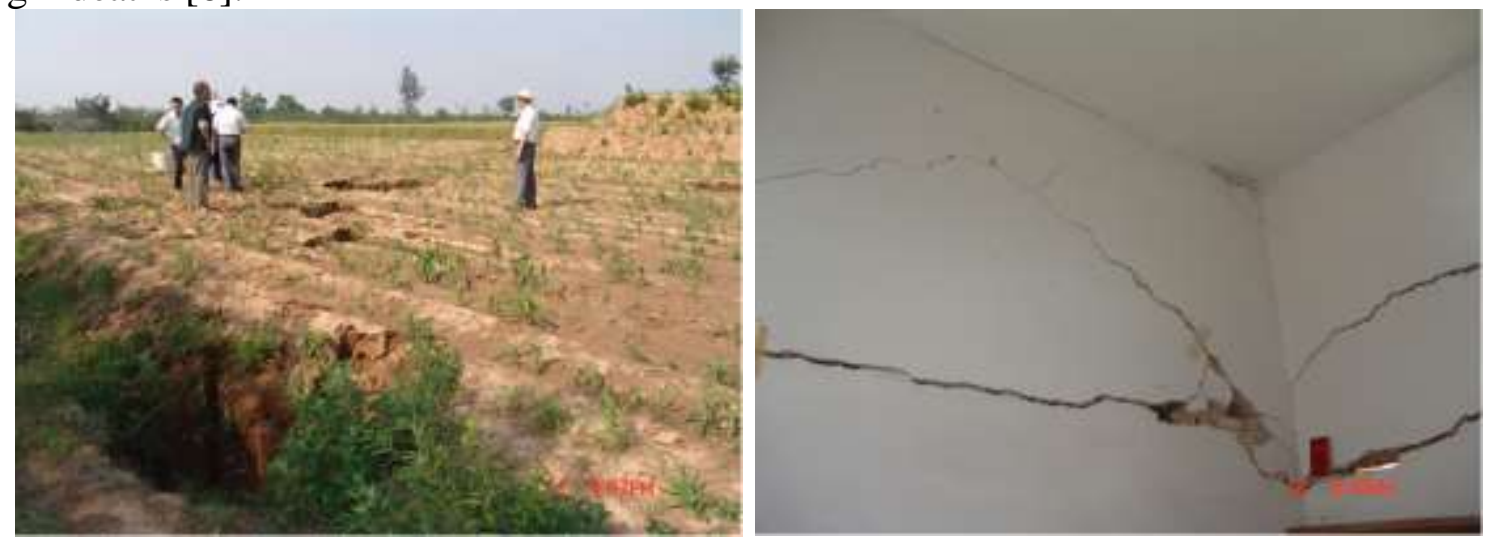

Figure 2. Finite Subsidence and house cracking caused by coal mining

Main Geological Environment Problems in Cement Limestone Mining Area. Limestone distributed on both sides of the G65 Baomao highway and the Eastern District of Yaozhou. Strip mining, stripping topsoil, destroying farmland and forest vegetation are wide spread in this region. A large number of limestone mines distributed near highway, city and surrounding yaowangshan tourism scenic areas, affecting the traffic and pedestrian safety, destruction of the ecological environment of stone exposed rock surface, affecting the visual landscape (Fig. 3). 


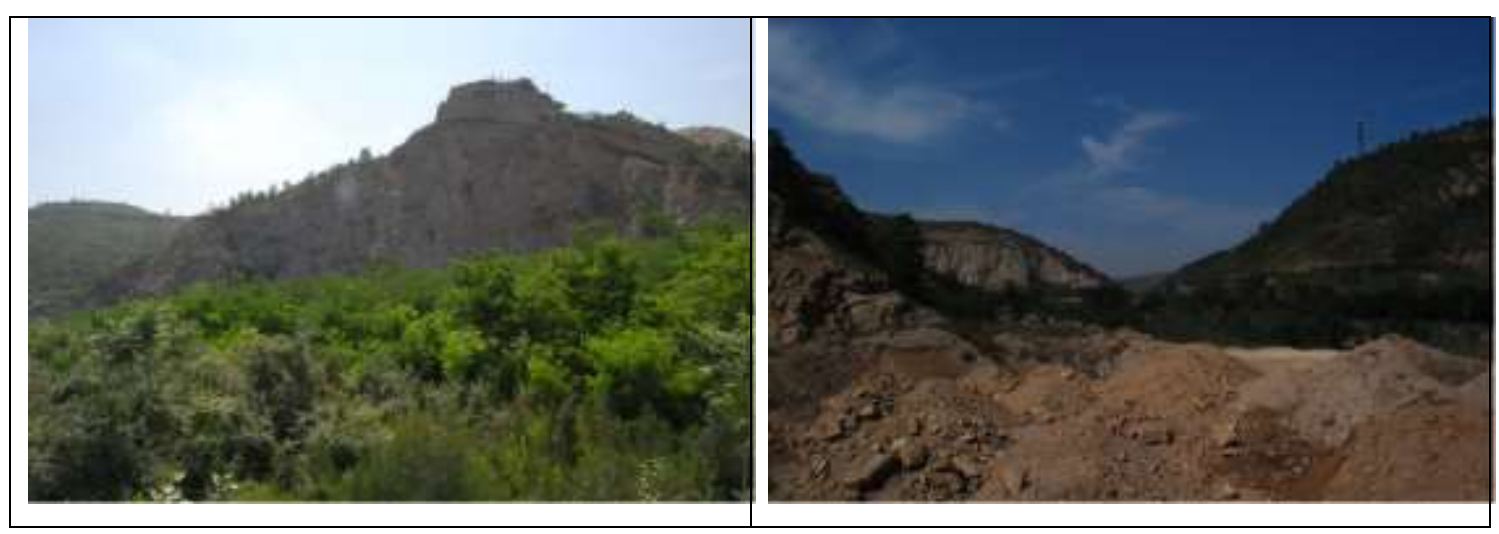

Figure 3. Finite Influence of limestone mining on ecological environment

Main Geological Environment Problems in Clay Mining Area. Refractory clay minerals are mainly distributed in the southwest of the city of Tongchuan Chenlu area, mainly for small private mines, because the seam changes, poor quality, the history of mining enterprises has many bankruptcy or discontinued. Strip the destruction of farmland, soil vegetation, slag heap row disorder caused by the mountain area, poor stability, damage road, influence and destruction of national ceramic town protection and tourism landscape, and the loose residue and soil erosion and the formation of collapse and debris flow geological hazards (Fig. 4).
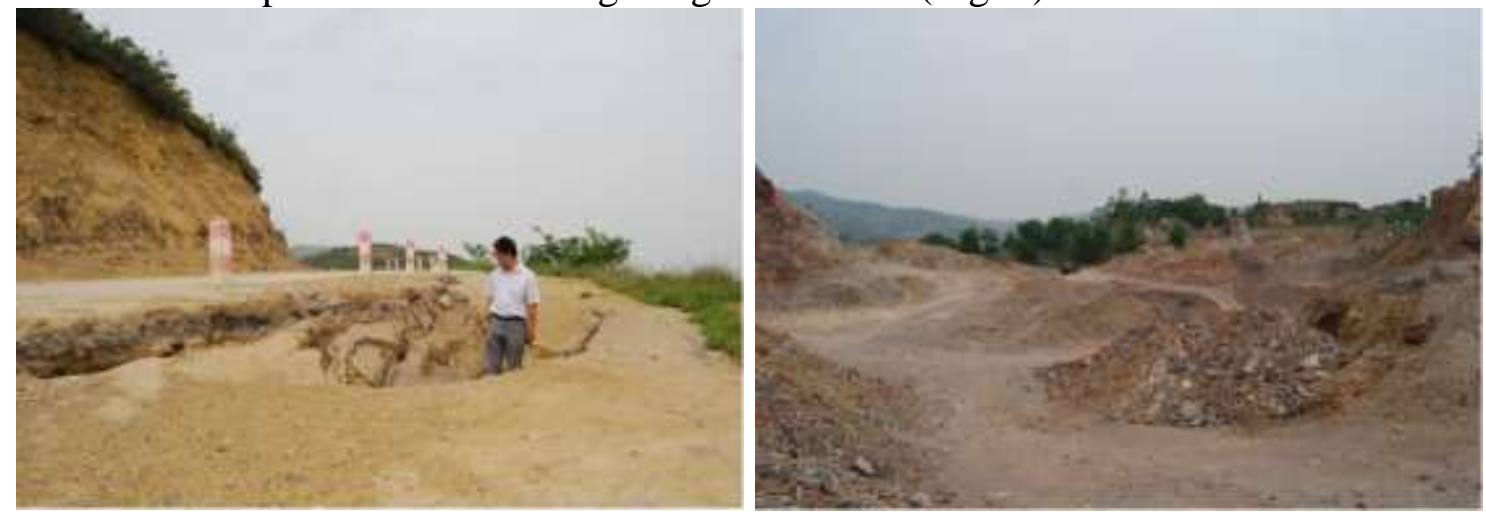

Figure 4. Finite Underground mining of clay minerals leads to the collapse of highway subgrade and damage of natural landscape

Countermeasures for Sustainable Development in Tongchuan. After decades of high strength mineral exploitation, Tongchuan's mining economy has gone from bad to worse, and the accumulation of history has become a prominent problem. Lack of jobs, imperfect urban functions, large ecological environment constraints, extensive renovation of shanty towns, backward infrastructure, lack of social security and other heavy burdens have made urban development difficult. Therefore, to seize the country to support policy opportunities for economic transformation of Resource-based City, Tongchuan City, starting from the geographical features, resource characteristics and policy environment characteristics of Tongchuan city transformation goal, transformation mode, focusing on the transition to make forward-looking, overall planning and strategic arrangement, helps to speed up the future construction and sustainable development of Tongchuan City, a to promote the transformation of Tongchuan city.

1, Further strengthen the leadership of economic transformation work. The work of economic transformation as Tongchuan city to lead the development of the leaping development of a political task and strategic measures, strengthen the Tongchuan City Economic Transition of the resource exhausted city leading group functions, timely report to the city transformation plan approval organization and implementation plan. Establish a compensation system for resources development and a sustainable development fund system for coal industry, so as to provide a mechanism guarantee for promoting economic transformation. 
2, Increase the comprehensive development and utilization of resources. Increase the investment in Tongchuan's circular economy, focus on coal, electricity, aluminum, cement and joint production of the circular economy industrial chain, and promote the deep development of resources and multi-level transformation value-added. Develop all kinds of cement products, and effectively improve the utilization ratio of cement limestone. Exploration and development of coalbed methane, rational exploitation and utilization of oil shale, kaolin and other valuable resources. To increase the comprehensive utilization of resources and efforts were associated with tailings and waste, strengthen the comprehensive evaluation of tailings resources, comprehensive utilization of fly ash and other industrial waste residue, and gradually realize the recovery of valuable elements in tailings re-use, improve economic efficiency.

3, Speed up industrial restructuring. Centering on the goal of the new industrial city construction in modern building materials industry as the leading industry, relying on the existing resources and conditions, further optimize the industrial structure, the traditional industries with high technology and advanced applicable technologies, the formation of a new leading industry [7] as soon as possible. The quality of electrolytic aluminum, cement, ceramics and other products as the focus, focus on the development of modern energy and chemical industry, building materials industry, at the same time, in order to foster the development of fruit, livestock and food for the characteristics of modern agriculture and agricultural product processing industry, vigorously cultivate the construction of electric power supply, equipment manufacturing, food, medicine, tourism and other alternative industries.

4, Strengthen environmental comprehensive improvement. Establish and improve the long-term mechanism of comprehensive improvement of urban environment. We will carry out pollution control in cement enterprises, comprehensive control of bituminous coal, gasification of natural gas, urban central heating, sewage and garbage disposal, and protect the urban environment. The implementation of the comprehensive renovation of the city center, riverside landscape greening, Ju Qishuihe River comprehensive management, river section in Yaozhou city park project, the transformation of the city landscape. The implementation of the rice shaped Easy Access, natural forest protection, slope greening, intuitive water environment protection and restoration, watershed management, soil and water conservation in the Yellow River dam construction, ecological engineering treatment of abandoned mines ecological construction projects, improve the city environment. Actively guide social forces to participate in mine environmental governance and waste land reclamation, and try to set up a specialized mining management company, study and formulate mine control planning and organize the implementation. Consolidate the fruits of returning farmland to forests, and continuously increase the forest coverage. Establish and improve the mineral development harm prevention and early warning mechanism of geological structure, groundwater hydrology, major geological disasters open pit, coal gangue and other hazards prevention of waste, effectively prevent spontaneous combustion and collapse events.

5, Further promote the coal mine goaf subsidence comprehensive treatment. In accordance with the "overall planning, step-by-step implementation of government guidance and market operation, personal investment, government help, in accordance with the law reform, to ensure a stable, working principle, responsible for the classification are respectively arranged" and the "first hit after the disaster, the first light town village, the first after the bankrupt enterprise production enterprises" governance in order to increase coal mining subsidence district comprehensive management. The implementation of "downhill" and "coal mining subsidence area" overall resettlement project, in the northern city, the southern city and the Mining Bureau of independent industrial and mining areas to build residential areas, and gradually solve the resettlement of residents of mined out areas.

6, Do a good job in employment and reemployment. Strict implementation of national, provincial and municipal a series of employment and reemployment support policies. We will further optimize the existing training resources, vigorously develop vocational and technical education and vocational training, and increase the free reemployment training for laid-off workers in urban areas and laid-off workers in state-owned enterprises. We should focus on screening a batch of labor-intensive projects, speed up construction, and play an important role in attracting 
labor force to obtain employment. We will actively develop the service sector and increase reemployment. The development of agriculture and rural economy and increase employment organically, actively develop labor-intensive and efficient characteristics, brand agriculture, accelerate the formation of major economic regions and villages, towns with different structure and characteristics, and strive to make the most of the new rural labor force transfer. We should actively implement the "go out" strategy, establish a labor resource base, and further increase the export of labor services.

7, Improve their ability to develop. Further improve the investment environment, improve efficiency, and constantly innovative ways to attract investment, attract more projects settled in Tongchuan. Establish and improve the city innovation system, accelerate the implementation of the new business service center, Tongchuan Vocational and Technical College, employment training centers and other projects, planning and construction of science and technology business incubator, high-tech training bases and other projects, enhance the vitality of city development. Accelerate the implementation of scientific and technological innovation, network information platform, personnel training base, special technology industry parks and other projects, improve the support capacity of science and education for economic development. Accelerate the implementation of urban landscaping, streets and alleys road reconstruction, new building materials industry, logistics centers and other projects to enhance urban development capacity. Speed up the implementation of agricultural water-saving irrigation, rural safe drinking water, rural roads and other projects to improve rural economic development capacity. Accelerate the implementation of education, employment and re employment of urban and rural residents, income, environment pollution, social security, housing security, coal mining subsidence area renovation, comprehensive management and shantytowns of rural infrastructure construction, construction, public health and sports culture of urban and rural community service system "the livelihood of the ten projects, efforts to eliminate the resource type city of intergenerational transmission of poverty the phenomenon, strengthen the competitiveness of the city, so that people get more benefits.

\section{References}

[1] Tang Yichuan, Jiao Xupeng, Feng Xin, Liu Botao and Xue Yaoqiong. Research on the countermeasures of the abandoned mines in Tongchuan, Shaanxi. Gansu Science and Technology, 30 (6), 22-24, 2014.

[2] Qu Wenjie. Exploration borehole drilling in the Henggou well field of the Wubu coal-mining district of the Permo-Carboniferous coal fields in the north of Shaanxi. Geology of Shaanxi. 23 (2), 90-93, 2005.

[3] The government of Tongchuan city. Implementation plan of key projects for mine geological environment treatment in resource exhausted cities of Tongchuan, report, 2010.

[4] Li Yonghong, Teng Hongquan, He Weizhong, Li Hui, He Yiping. Planning for geo-hazard prevention and control in Tongchuan Shaanxi. Journal of Geological Hazard and Environment Preservation. 25(2), 40-48, 2014.

[5] Huang Meitao, Bai Youshe. Comprehensive treatment of geological environment in Sanlidong coal mine, Tongchuan. Western Ore Exploration Engineering. 3, 121-122, 2013.

[6] Yan Jiaqi, Yang Meizhong and Zheng Shouquan. Geological disaster and preventive measures of Tongchuan mining area. Journal of Xi' an Mining Institute. 1, 31-35, 1993.

[7] Liu Rong, Shi Xingmin and Liu Hao. The assessment and trend of sustainable development of Tongchuan City. Journal of Northwest University. 41 (5), 901-906, 2012. 